\title{
Multiplex picoliter-droplet digital PCR for quantitative assessment of EGFR mutations in circulating cell-free DNA derived from advanced non-small cell lung cancer patients
}

\author{
QIAN YU ${ }^{1}$, FEI HUANG ${ }^{1}$, MEILIN ZHANG ${ }^{2}$, HAIYING JI ${ }^{2}$, SHENCHAO WU ${ }^{1}$, YING ZHAO ${ }^{1}$, \\ CHUNYAN ZHANG ${ }^{1}$, JIONG WU $^{1}$, BEILI WANG ${ }^{1}$, BAISHENG PAN $^{1}$, XIN ZHANG $^{2^{*}}$ and WEI GUO ${ }^{1 *}$ \\ Departments of ${ }^{1}$ Laboratory Medicine and ${ }^{2}$ Pulmonary Medicine, Zhongshan Hospital, Fudan University, \\ Shanghai 200032, P.R. China
}

Received June 15, 2016; Accepted April 13, 2017

DOI: $10.3892 / \mathrm{mmr} .2017 .6712$

\begin{abstract}
To explore the possible diagnostic value of liquid biopsy, two multiplex panels using picoliter-droplet digital polymerase chain reaction (ddPCR) were established to quantitatively assess the epidermal growth factor receptor $(E G F R)$ mutations in cell-free DNA (cfDNA) extracted from the plasma of advanced non-small cell lung cancer (NSCLC) patients. Plasma samples derived from 22 patients with stage IIIB/IV NSCLC harboring EGFR mutations in matched tumor tissues confirmed by amplification refractory mutation system (ARMS) analysis were subjected to two multiplex ddPCR panels to assess the abundance of tyrosine kinase inhibitor (TKI) -sensitive (19DEL, L858R) and TKI-resistant (T790 M) mutations. Fluctuations in EGFR mutant abundance were monitored by either of the multiplex ddPCR panels for three patients undergoing EGFR-TKI treatment, with serial plasma sample collections over 2 months. The multiplex
\end{abstract}

Correspondence to: Professor Wei Guo, Department of Laboratory Medicine, Zhongshan Hospital, Fudan University, 180 Fenglin Road, Shanghai 200032, P.R. China

E-mail: guo.wei@zs-hospital.sh.cn

Professor Xin Zhang, Department of Pulmonary Medicine, Zhongshan Hospital, Fudan University, 180 Fenglin Road, Shanghai 200032, P.R. China

E-mail: zhang.xin@zs-hospital.sh.cn

*Contributed equally

Abbreviations: ddPCR, picoliter-droplet digital polymerase chain reaction; EGFR, epidermal growth factor receptor; cfDNA, circulating cell-free DNA; NSCLC, non-small cell lung cancer; EGFR-TKIs, epidermal growth factor receptor-tyrosine kinase inhibitors; 19DEL, exon 19 deletions; L858R, exon 21 L858R mutations; T790M, exon 20 T790M mutation; LOB, limit of blank

Key words: non-small cell lung cancer, epidermal growth factor receptor, picoliter-droplet digital PCR, circulating cell-free DNA, liquid biopsy
ddPCR panels applied to plasma cfDNA from advanced NSCLC patients achieved a total concordance rate of $80 \%$ with the EGFR mutation profiles obtained by ARMS from matched biopsy tumor specimens (90\% for 19DEL, 95\% for L858R, 95\% for T790M, respectively) and revealed additional mutant alleles in two subjects. The respective sensitivity and specificity were 90.9 and $88.9 \%$ for 19DEL, 87.5 and $100 \%$ for L858R, 100 and $93.8 \%$ for T790M. The fluctuations of EGFR mutant abundance in serial plasma cfDNA were in accordance with the changes in tumor size as assessed by imaging scans. The authors demonstrated the utility of multiplex ddPCR panels with ultra-sensitivity for quantitative analysis of $E G F R$ mutations in plasma cfDNA and obtained promising usefulness in EGFR-TKI decision-making for advanced NSCLC patients.

\section{Introduction}

Non-small cell lung cancers (NSCLCs) account for $>80 \%$ of all lung cancers and represent the leading cause of cancer mortality worldwide, and in China alone $(1,2)$. Most NSCLC patients are initially diagnosed with advanced-stage disease, which is defined as an unresectable, widely metastatic tumor and is followed by poor prognosis.

Epidermal growth factor receptor-tyrosine kinase inhibitors (EGFR-TKIs) are helpful for patients with EGFR-activating mutations, especially exon 19 deletions (19DEL) and exon 21 L858R mutations (L858R), which account for $85 \%$ of all clinically important mutations (progression-free survival (PFS) was 13.1 months with erlotinib compared to 4.6 months with platinum-based chemotherapy and 8.0 months with gefitinib compared to 6.3 months with platinum-based chemotherapy) $(3,4)$. However, on average, most patients undergoing EGFR-TKI treatment develop resistance within 1 year $(5,6)$, and $>50 \%$ of them carry the exon 20 T790M mutation (T790 M) in EGFR (7). Recently, the efficiency of AZD9291, a third-generation EGFR-TKI, was demonstrated in lung cancer patients resistant to prior therapy with EGFR-TKIs who harbored T790M (PFS was 9.6 months in T790M-positive patients and 2.8 months in T790M-negative patients) (8). Increasing evidence has suggested that there may be a low-abundance, 
intrinsic T790M mutation prior to EGFR-TKI therapy (9-11), which enforces the need for exploring T790M status before treatment. American Society of Clinical Oncology, European Society for Medical Oncology and National Comprehensive Cancer Network guidelines recommend clarifying EGFR mutation profiles before TKI therapy or after the emergence of TKI resistance to provide a precise and effective therapeutic regimen (12-14).

DNA extracted from tumor tissue remains the major source for mutation analysis in clinical settings. Circulating cell-free DNA (cfDNA) in plasma provides a homogeneous representation of all tumor DNA and can help implement non-invasive, continual monitoring of tumor mutation profiles while obviating the reliance on invasive biopsies, tissue archives and tumor heterogeneity. However technical challenges remain in analyzing plasma cfDNA for EGFR mutations, such as the low quantity and variability in the tumor-derived cfDNA fraction between individuals.

Picoliter-droplet digital polymerase chain reaction (ddPCR) is a promising approach with ultra-sensitive detection and absolute quantification. This method compartmentalizes samples into millions of picoliter droplets containing single DNA molecules and analyses the terminal fluorescence of each droplet after parallel amplification. Multiplex ddPCR can effectuate multiple mutation assays simultaneously in one well with minimal DNA sample consumption (15).

This study developed two multiplex ddPCR panels for quantitative analysis of treatment-related EGFR mutations in plasma cfDNA and compared the results generated by multiplex ddPCR assays on plasma samples and by amplification refractory mutation system (ARMS) assays on matched tumor tissue specimens from advanced NSCLC patients.

\section{Materials and methods}

Design of the multiplex ddPCR panels. The authors developed two independent multiplex ddPCR panels for clinical application, a 4-plex panel for 19DEL and T790M mutations plus the corresponding wild-type assays and a 5-plex panel to identify L858R (L858R-1 and L858R-2) and T790M mutations.

Tables I and II present the sequences and concentrations of primers and TaqMan ${ }^{\circledR}$ probes (Thermo Fisher Scientific, Inc., Waltham, MA, USA) used $(16,17)$. Probes for 19DEL were targeted at in-frame deletions in exon 19 of the EGFR polypeptide. The probes recognized c. $2573 \mathrm{~T}>\mathrm{G}$ for $\mathrm{L} 858 \mathrm{R}-1$, c. $2573 \mathrm{~T}>\mathrm{G}$ and c. $2574 \mathrm{G}>\mathrm{T}$ for L858R-2, and c. $2369 \mathrm{C}>\mathrm{T}$ for T790M. The PCR mixture for each multiplex panel consisted of $20 \mu \mathrm{l}$ TaqMan ${ }^{\circledR}$ Genotyping Master Mix (Thermo Fisher Scientific, Inc.), 1.6 $\mu 1$ Droplet Stabilizer (RainDance Technologies, Lexington, MA, USA), forward and reverse primers, and probes in different concentrations and contained at least $50 \mathrm{ng}$ of target DNA template to a final reaction volume of $40 \mu 1$.

Plasmid DNA preparation and DNA controls. The performance of each ddPCR assay was assessed using fragmented plasmid DNA containing wild-type or mutant EGFR sequence. Plasmids carrying wild-type (Plasmid \#11011) or 19DEL mutant (Plasmid \#32062) sequences were purchased from Addgene (http://www.addgene.org). The point mutations L858R-1, L858R-2 and T790M were introduced using a Phusion Site-Directed Mutagenesis kit (Thermo Fisher Scientific, Inc.), following the manufacturer's procedure (18), and were confirmed by Sanger sequencing. Plasmid containing mutant sequence was serially diluted with plasmid containing wild-type sequence to yield a mixture in which the mutant copy number was approximately $0.01-10 \%$ of the wild-type copy number.

Patients and sample collection. The EGFR mutation status of 33 plasma samples was assessed from 25 NSCLC patients with stage IIIB/IV cancers that were enrolled from Zhongshan Hospital (Shanghai, China) from January 2015 to December 2015 and harbored EGFR mutations, confirmed by ARMS analysis of tumor tissue. Tumor specimens in the present study were taken for clinical diagnostic purpose, which from the 19 patients were obtained before EGFR-TKI therapy and re-biopsies from 3 patients were taken after acquiring resistance to EGFR-TKIs. Contemporaneous plasma samples were subjected to the multiplex ddPCR panels. Another 3 patients were treated with gefitinib at the physician's discretion and were recruited for serial plasma samples collection at 2-month intervals to monitor the fluctuations in EGFR mutation abundance by ddPCR assays. These patients also received the appropriate imaging diagnoses, including computed tomography scans performed for Response Evaluation Criteria in Solid Tumors-based treatment response evaluation (19). The study was approved by the Ethics Committee of Fudan University (Shanghai, China) and informed consent was obtained from the all for use of the blood sample and tumor tissue.

DNA extraction. Peripheral blood samples $(10 \mathrm{ml})$ were collected into EDTA-K $\mathrm{K}_{2}$ containing tubes. Blood samples were centrifuged for $10 \mathrm{~min}$ at $1,900 \mathrm{x} \mathrm{g}$ to obtain preliminary supernatants within $2 \mathrm{~h}$ following sampling. Afterwards, another centrifugation at $16,000 \mathrm{xg}$ for $10 \mathrm{~min}$ at $4^{\circ} \mathrm{C}$ separated the plasma samples from the blood cell pellet. Circulating cfDNA was extracted using a QIAamp Circulating Nucleic Acid kit (Qiagen GmbH, Hilden, Germany) according to the manufacturer's instructions and was eluted with $50 \mu \mathrm{l}$ Tris-EDTA buffer. All tumor specimens were collected for diagnostic purpose by tracheobronchoscopy, percutaneous puncture biopsy or metastatic lymph node biopsies and reviewed by a pathologist for tumor cell content. The tumor tissue DNA was extracted from formalin-fixed and paraffin-embedded diagnostic specimens using a QIAamp DNA FFPE Tissue kit (Qiagen $\mathrm{GmbH}$ ) following the manufacturer's instructions and was eluted with $100 \mu \mathrm{l}$ Buffer AE (Qiagen GmbH, Hilden, Germany). The extracted cfDNA and tumor tissue DNA concentrations were measured with a NanoDrop ND-1000 spectrophotometer (Thermo Fisher Scientific, Inc.).

EGFR mutations in tumor tissue specimens detected by ARMS. EGFR mutations in tumor tissue specimens were detected using an ADx-ARMS kit (Amoy Diagnostics, Xiamen, China), which was approved by the Chinese Food and Drug Administration for in vitro diagnostic use. All experiments and genotype determinations were performed according to the manufacturer's instructions and as previously described (20). 
A

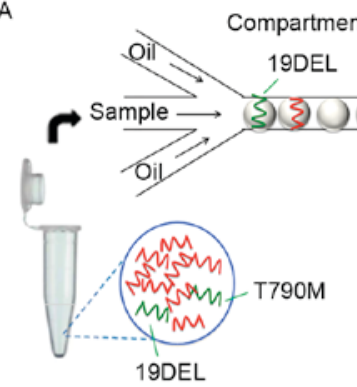

C

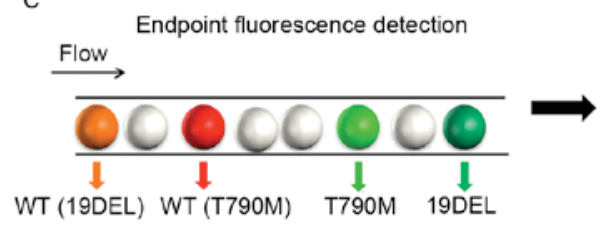

into droplets

T790M

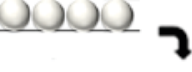

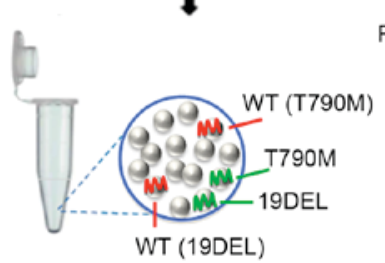

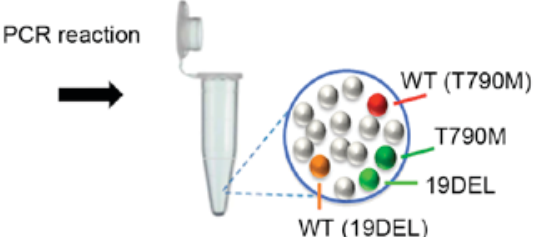

D
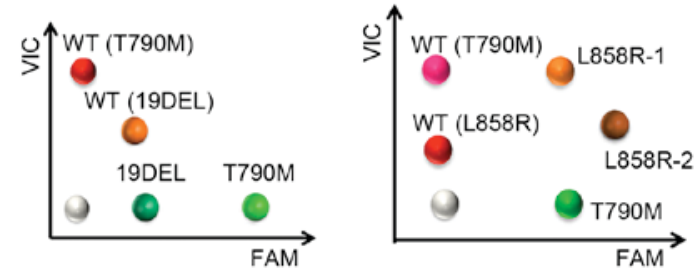

Figure 1. Workflow of the multiplex ddPCR panels. (A) The PCR mixture for each assay consisted of DNA templates, primer pairs, probes, master mix and stabilizer to a final volume of $40 \mu 1$ and was (B) compartmentalized into $>5$ million picoliter-sized droplets for independent PCR reactions. (C) The endpoint fluorescence signal of each droplet was scanned and analyzed. (D) Different fluorophores and diverse end point fluorescence intensities distinguished the droplets containing target templates into different clusters. ddPCR, picoliter-droplet digital polymerase chain reaction; WT, wild-type; 19DEL, exon 19 deletions; L858R-1, exon 21 L858R mutation (c.2573T>G); L858R-2, exon 21 L858R mutation (c.2573T>G, c.2574G>T); T790M, exon 20 T790M mutation; FAM, 6-carboxyfluorescein; VIC, green fluorescent protein.

and the results from ARMS assays of matched tumor tissue specimens was calculated using a $\kappa$ test. A paired Student's t-test was applied to analyze the discrepancy in the abundance of T790M as measured by both multiplex ddPCR panels. The linearity range was assessed using the linear correlation coefficient values $\left(\mathrm{r}^{2}\right)$ and slope. $\mathrm{P}<0.05$ was considered to indicate a statistically significant difference.

\section{Results}

Multiplex ddPCR panels detected the three most common EGFR mutations. Droplet digital PCR assays compartmentalize the reaction mixture into millions of picoliter-sized droplets so that each contains only one DNA string as the template, and an independently PCR is then performed within the droplets in parallel. Multiplex ddPCR panels can efficiently detect multiple mutations simultaneously in one assay with minimal sample consumption. The abridged general view of the workflow is described in Fig. 1. Different fluorophores and a diverse end point fluorescence intensity determined by the concentration and combination use of TaqMan ${ }^{\circledR}$ probes distinguished the droplets containing specific target templates into different clusters in a 2-dimensional histogram. The cluster representing 19DEL or L858R is located along the diagonal line for the VIC and FAM co-conjugated probes used (as presented in Fig. 2).

Performance assessments of the multiplex ddPCR panels. As the defining characteristic of an assay, the LOB determines the lower limit of detection. The authors subjected fragmented plasmids containing only wild-type sequence to both multiplex ddPCR panels in 24 replicates to observe the false-positive events in each mutant assay, which allowed us to generate the
LOB (the count distribution is presented in Fig. 3). A Poisson model was applied to fit the false-positive distribution, and the LOB was determined using the $95 \%$ confidence interval. The LOBs were 5 for 19DEL, 3 for L858R-1, 3 for L858R-2, and 7 for T790M (the LOB for T790M generated from the two panels was the same, data not shown). To assess the specificity of the panel assays, plasmids containing either the L858R-1 or the L858R-2 sequence, which have only one base difference between them, were subjected to the 5-plex panel in triplicate; no cross-reactivity was observed (all false-positive events were less than the LOB, data not shown).

The quantitative performance of multiplex ddPCR panels was assessed using a series of dilutions from fragmented plasmid sequences (Fig. 4). Each dilution was analyzed in triplicate, and the averaged results were plotted on 2-dimensional histograms (as shown in Fig. 4A and C for each panel). The mutant allele expected copy number was plotted against the actual copy number (Fig. 4B and D), and regression analysis revealed a strong correlation (the slopes were 1.008 for 19DEL, 1.007 for T790M, 0.996 for L858R-1, and 0.992 for L858R-2; all slopes had $\mathrm{r}^{2}$ values greater than 0.990$)$. Detectable abundance ranged from 0.01 to $10 \%$. There was no significant difference between the T790M abundance in the same sample by either panel $(\mathrm{t}=1.386, \mathrm{P}>0.05)$. Therefore, it follows that the quantitative analysis of 19DEL, L858R-1, L858R-2 and T790M using these two multiplex ddPCR panels is reliable and has ultra-sensitivity, which allows the detection and quantification of mutant alleles, even at ultra-low ratios $(0.01 \%)$.

Multiplex ddPCR analysis of EGFR mutations in circulating cfDNA from patients with advanced NSCLC. To demonstrate the feasibility of applying these two multiplex panels to clinical practice, analysis was performed on plasma samples 


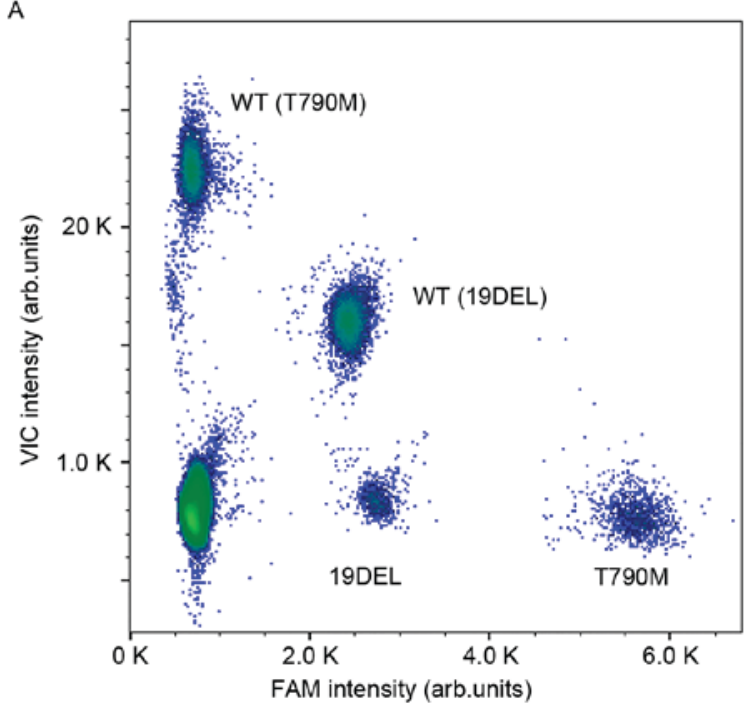

B

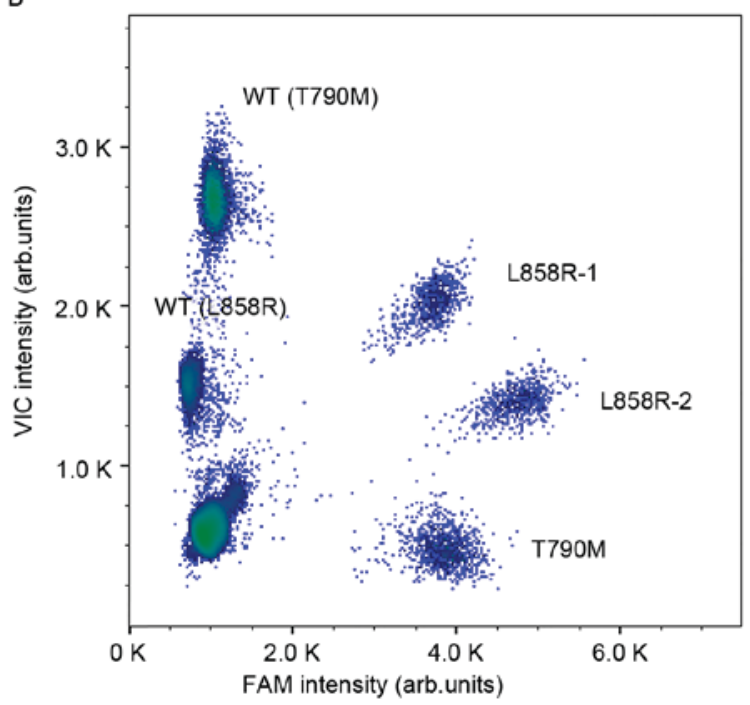

Figure 2. Multiplex picoliter-droplet digital polymerase chain reaction panels for EGFR mutation assays. Two-dimensional histograms of the (A) 4-plex and the (B) 5-plex panels. EGFR, epidermal growth factor receptor; FAM, 6-carboxyfluorescein; VIC, green fluorescent protein; WT, wild-type; 19DEL, exon 19 deletions; L858R-1, exon 21 L858R mutation (c.2573T>G); L858R-2, exon 21 L858R mutation (c.2573T>G, c.2574G>T); T790M, exon 20 T790M mutation.

A

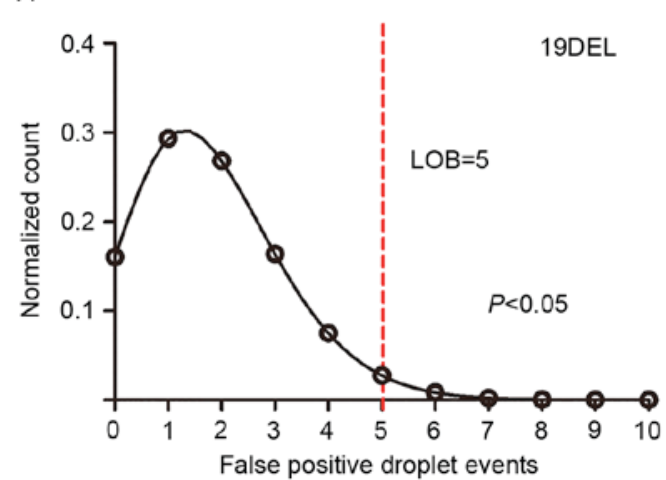

C

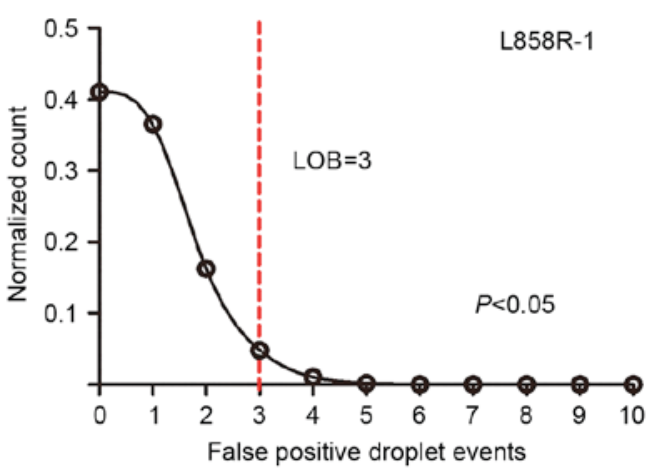

B

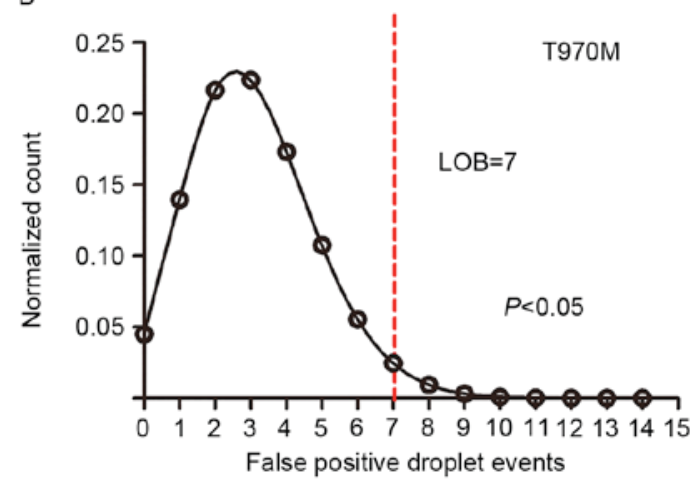

D

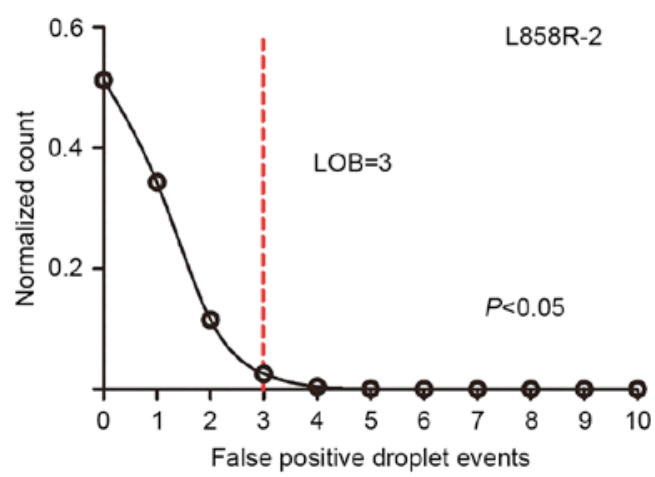

Figure 3. The limit of blank for the multiplex ddPCR panels is generated by observing the false-positive droplet events in assays for each mutant with wild-type templates. Fragmented plasmid containing only wild-type sequence was subjected to the 4-plex and 5-plex panel in 24 replicates. Presented here are the frequency distributions of false-positive events for (A) 19DEL, (B) T790M, (C) L858R-1 and (D) L858R-2. A Poisson model was applied to fit the frequency distribution and LOB for each, as determined by the 95\% confidence interval following regression analysis, which is presented by the red cutoff line. 19DEL, exon 19 deletions; L858R, exon 21 L858R mutation; T790M, exon 20 T790M mutation; LOB, limit of blank.

collected from 22 patients with advanced NSCLC whose EGFR mutation profiles had been obtained by ARMS in contemporaneously collected tumor tissues (Table III). The inter-individual concentrations of extracted plasma cfDNA 
A Concentration (mutant/wild-type copy number)
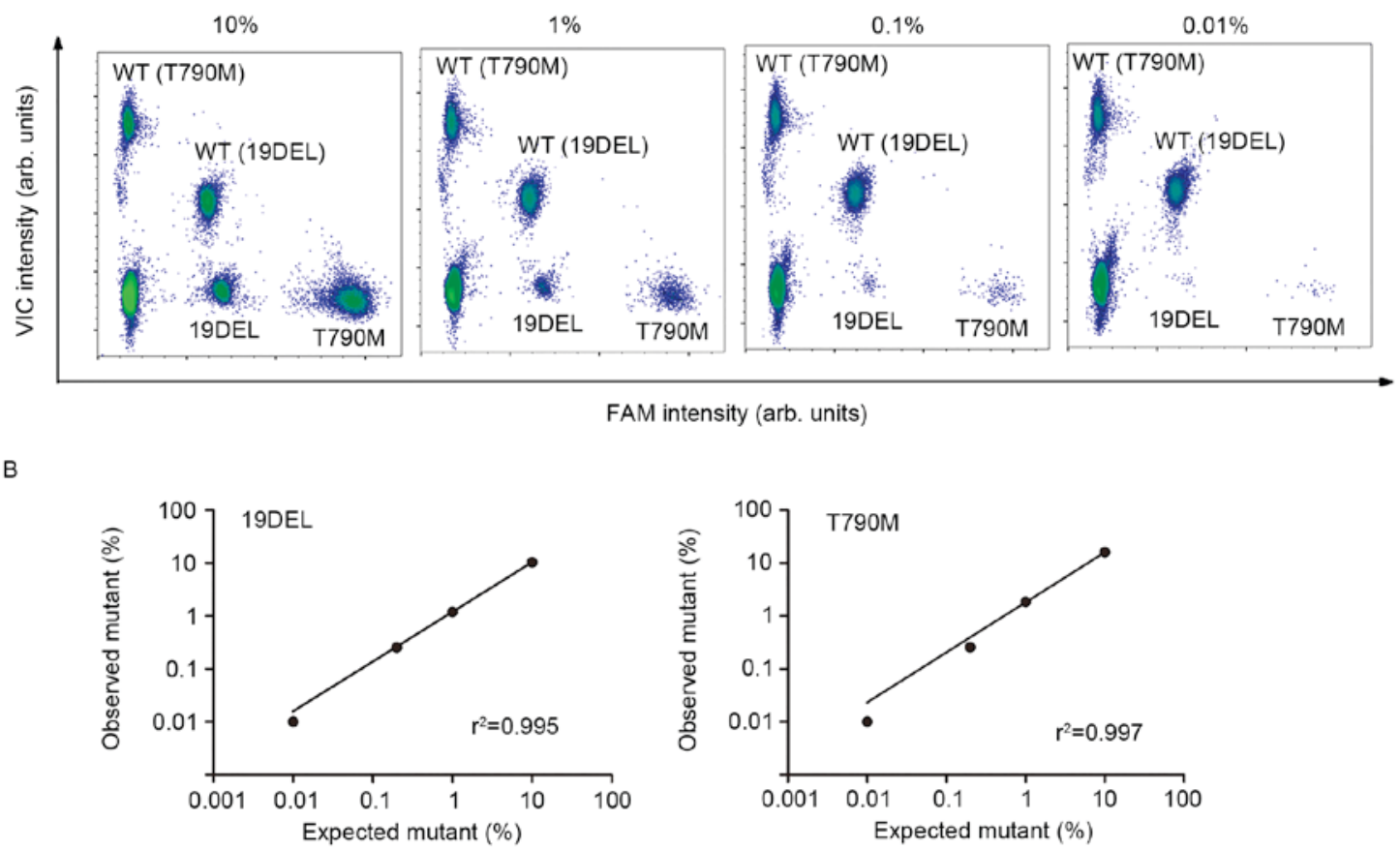

FAM intensity (arb. units)

C

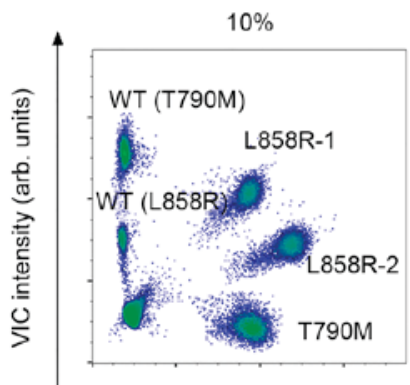
Concentration (mutant/wild-type copy number)
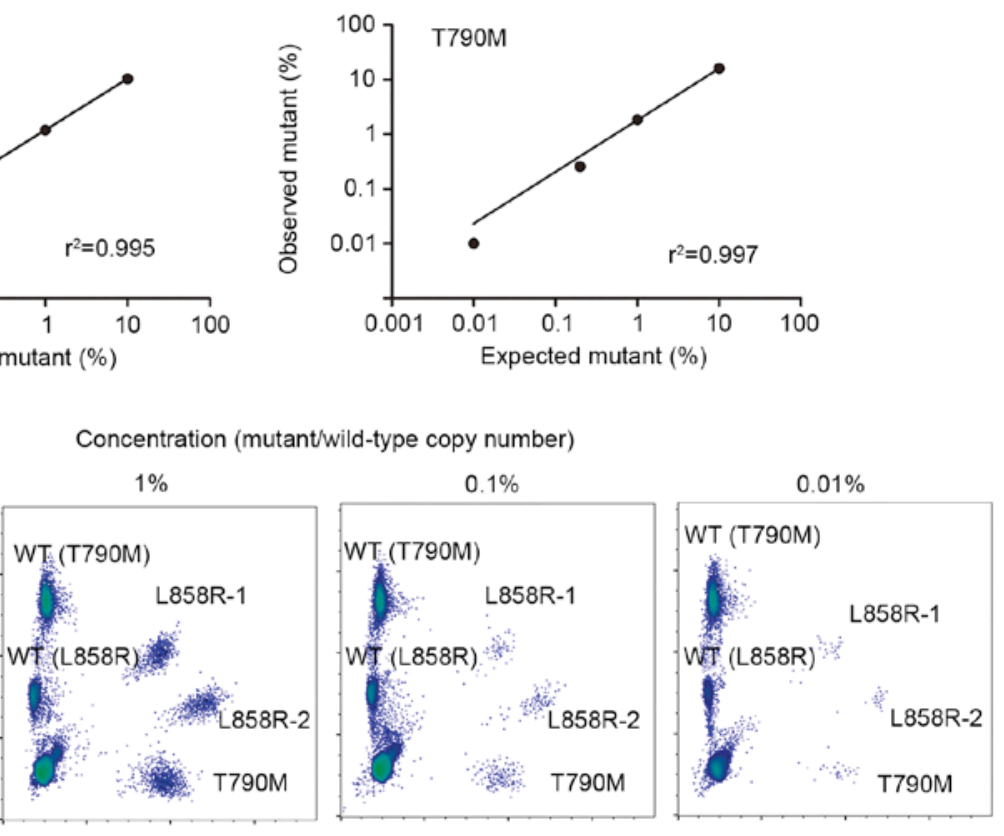

FAM intensity (arb. units)

D
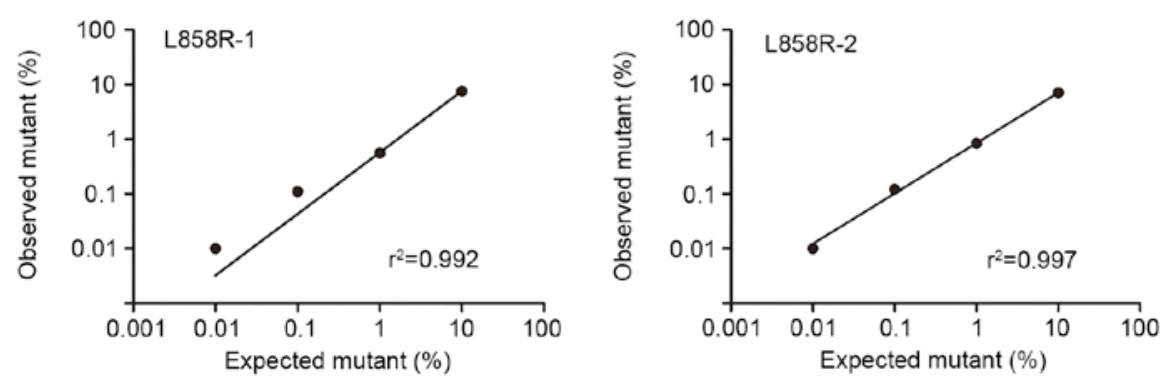

Figure 4. Performance of the multiplex ddPCR panels for quantifying EGFR mutants. Samples with descending mutant abundance were subjected to the 4-plex (A) and 5-plex (C) ddPCR panels. Simple linear regression analysis was applied to the expected abundances of mutant alleles and was plotted against the detected abundances of the 4-plex (B) or 5-plex (D) panels. ddPCR, picoliter-droplet digital polymerase chain reaction; EGFR, epidermal growth factor receptor; FAM, 6-carboxyfluorescein; VIC, green fluorescent protein; 19DEL, exon 19 deletions; L858R-1, exon 21 L858R mutation (c.2573T>G); L858R-2, exon 21 L858R mutation (c.2573T>G, c.2574G>T); T790M, exon 20 T790M mutation.

ranged from 16.4 to $102.5 \mathrm{ng} / \mu 1$, and concentration did not correlate with the content of particular mutant abundance (15). Adequate numbers of valid droplets with $>100$ counts ensured the validity of each assay; cases 9 and 17, which had no allotment for re-extraction, were excluded because they did not have enough droplets that detected wild-type templates. The overall concordance rate between EGFR mutation profiles obtained from plasma or tumor specimens was $80 \%(16 / 20)$. The concordance rates of the 19DEL, L858R and T790M assays were $90 \%(\mathrm{k}=0.798, \mathrm{P}<0.05), 95 \%(\mathrm{k}=0.894, \mathrm{P}<0.05)$, and $95 \%(\mathrm{k}=0.857 ; \mathrm{P}<0.05)$, respectively, with sensitivities and specificities of 90.9 and $88.9 \%$ for 19DEL, 87.5 and $100 \%$ for L858R, and 100 and $93.8 \%$ for T790M, respectively. The ARMS results from tumor tissue specimens were used as a 
Table III. Results generated from plasma cfDNA by multiplex ddPCR panels and tumor tissue DNA by ARMS in advanced NSCLC patients.

\begin{tabular}{|c|c|c|c|c|c|c|c|c|}
\hline \multirow[b]{2}{*}{ Case } & \multirow[b]{2}{*}{ Sex } & \multirow[b]{2}{*}{ Age (years) } & \multirow[b]{2}{*}{ Stage } & \multirow[b]{2}{*}{ EGFR-TKI } & \multirow[b]{2}{*}{ Site } & \multirow[b]{2}{*}{$\begin{array}{l}\text { ARMS on tumor } \\
\text { tissue DNA }\end{array}$} & \multicolumn{2}{|c|}{$\begin{array}{c}\text { Multiplex ddPCR panels } \\
\text { on plasma cfDNA }\end{array}$} \\
\hline & & & & & & & Mutant & $\begin{array}{c}\text { Abundance } \\
(\%)\end{array}$ \\
\hline 1 & M & 53 & IV & No & Lung & 19DEL & $19 \mathrm{DEL}^{\mathrm{a}}$ & 2.00 \\
\hline 2 & M & 53 & IV & No & Lung & 19DEL & 19DEL & 15.64 \\
\hline 3 & $\mathrm{~F}$ & 65 & IV & No & Lung & 19DEL & 19DEL & 4.81 \\
\hline 4 & M & 62 & IV & No & Lung & 19DEL & 19DEL & 45.68 \\
\hline 5 & $\mathrm{~F}$ & 41 & IV & No & Lung & 19DEL & 19DEL & 5.22 \\
\hline 6 & $\mathrm{~F}$ & 51 & IIIb & No & Lung & 19DEL & 19DEL & 19.62 \\
\hline 7 & M & 46 & IV & No & Lung & 19DEL & 19DEL & 12.93 \\
\hline 8 & $\mathrm{~F}$ & 64 & IV & No & Lung & 19DEL & $\mathrm{N}^{\mathrm{a}}$ & \\
\hline 9 & M & 61 & IV & No & Lung & 19DEL & $\mathrm{NE}$ & \\
\hline 10 & M & 47 & IV & No & Lung & L858R & L858R & 7.47 \\
\hline 11 & $\mathrm{M}$ & 71 & IIIb & No & Lung & L858R & $\mathrm{L}^{858 \mathrm{R}^{\mathrm{a}}}$ & 17.74 \\
\hline 12 & $\mathrm{~F}$ & 63 & IV & No & Lung & L858R & $\mathrm{L}^{858 \mathrm{R}^{\mathrm{a}}}$ & 1.32 \\
\hline 13 & $\mathrm{~F}$ & 58 & IV & No & Lung & L858R & L858R & 5.78 \\
\hline 14 & $\mathrm{~F}$ & 69 & IV & No & Lung & L858R & $\mathrm{L}^{858 \mathrm{R}^{\mathrm{a}}}$ & 5.63 \\
\hline 15 & M & 35 & IIIb & No & Lung & L858R & $\mathrm{L}^{858 \mathrm{R}^{\mathrm{a}}}$ & 3.15 \\
\hline 16 & $\mathrm{~F}$ & 66 & IIIb & No & Lung & L858R & $\mathrm{N}^{\mathrm{a}}$ & \\
\hline 17 & $\mathrm{~F}$ & 74 & IV & No & Lung & L858R & $\mathrm{NE}$ & \\
\hline 18 & M & 61 & IV & Gefitinib & Lung & T790M & $\mathrm{T} 790 \mathrm{M}^{\mathrm{a}}$ & 2.91 \\
\hline \multirow[t]{2}{*}{19} & $\mathrm{~F}$ & 48 & IV & Gefitinib & Lung & 19DEL & 19DEL & 27.54 \\
\hline & & & & & & T790M & T790M & 23.49 \\
\hline \multirow[t]{2}{*}{20} & $\mathrm{~F}$ & 62 & IV & Gefitinib & Lung & 19DEL & 19DEL & 8.64 \\
\hline & & & & & & T790M & T790M & 1.69 \\
\hline \multirow[t]{2}{*}{21} & $\mathrm{~F}$ & 72 & IV & No & Lung & 19DEL & 19DEL & 64.02 \\
\hline & & & & & & & $\mathrm{T} 90 \mathrm{M}^{\mathrm{a}}$ & 0.91 \\
\hline \multirow[t]{3}{*}{22} & M & 68 & IV & No & Lung/ & L858R & 19DEL & 8.17 \\
\hline & & & & & lymph node & T790M & L858R & 4.07 \\
\hline & & & & & & & $\mathrm{T} 90 \mathrm{M}^{\mathrm{a}}$ & 3.97 \\
\hline
\end{tabular}

${ }^{a}$ Assays were performed in triplicate and are presented as the mean values (droplet count between limit of blank and 20). ddPCR, picoliter-droplet digital polymerase chain reaction; cfDNA, circulating cell-free DNA; 19DEL, exon 19 deletions; L858R, exon 21 L858R mutations; T790M, exon 20 T790M mutation; site, biopsy site; EGFR-TKI, epidermal growth factor receptor tyrosine kinase inhibitor; NE, not evaluated; N, negative for three EGFR mutant types; ARMS, amplification refractory mutation system.

reference. Plasma cfDNA assays for cases 21 and 22 revealed additional mutant alleles that were not detected in tumor tissue specimens by ARMS. Therefore, the authors reanalyzed the DNA extracted from these tumor specimens in multiplex ddPCR panels and verified the mutations with ultra-low abundance $(0.29 \%$ for T790M in case 21 and $0.57 \%$ for $19 \mathrm{DEL}$ in the metastatic tumor biopsied from the lymph node in case 22; data not shown). However, two patients were negative for the expected mutations in plasma cfDNA, which had been detected by ARMS in tumor tissue specimens (19DEL in case 8 and L858R in case 16).

Therapeutic monitoring via the multiplex ddPCR panels. To investigate whether quantitative analysis of cfDNA $E G F R$ mutations by either multiplex ddPCR panel could help monitor treatment response and reveal therapeutic resistance, 3 patients were analyzed using 11 serially collected plasma samples during gefitinib administration. Fig. 5 demonstrated that the EGFR mutant abundance in plasma cfDNA fluctuated according to the change in tumor size as revealed by imaging scans.

Case 23 (Fig. 5A) is a 46-year-old male with no history of smoking with lung adenocarcinoma and brain metastasis harboring a 19DEL mutation, which was confirmed by ARMS in a tumor biopsy. The 4-plex panel (for assaying 19DEL and T790M) was applied to monitor the therapeutic response to gefitinib and noted a persistent decrease in 19DEL mutant abundance that was coincident with the change in the maximum tumor diameter. Case 24 (Fig. 5B) is a 56-year-old female non-smoker with stage IV lung adenocarcinoma who 


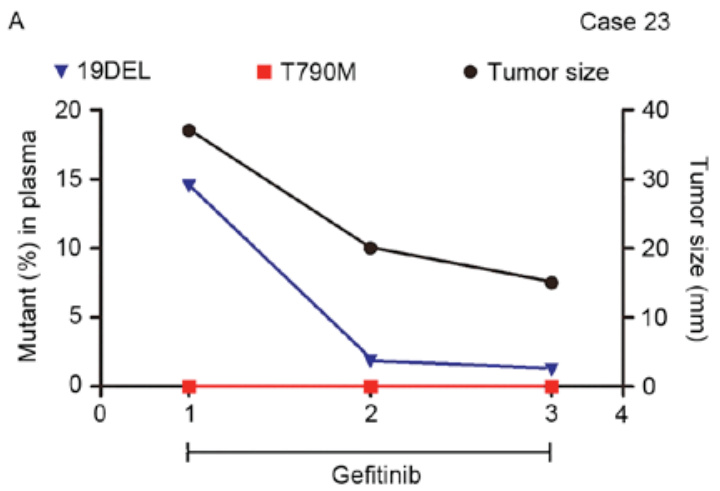

B
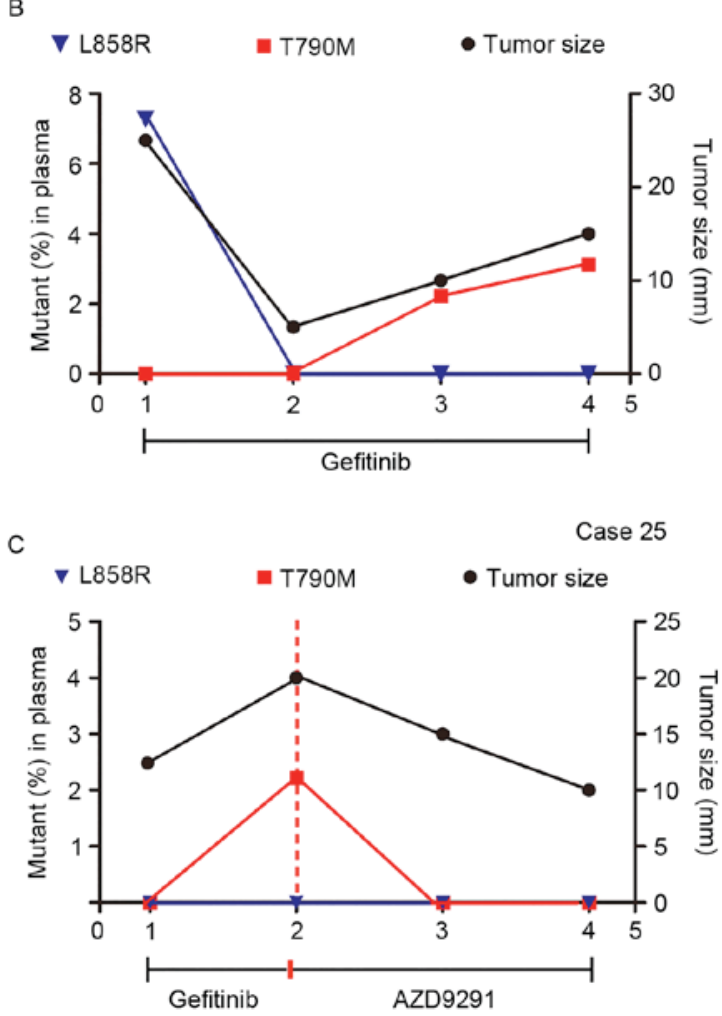

Figure 5. Therapeutic monitoring by multiplex picoliter-droplet digital polymerase chain reaction assays on plasma cfDNA EGFR mutations and lung mass imaging scans. Abundance of EGFR mutations in plasma cfDNA fluctuated with tumor size, as revealed by imaging scans. (A) 19DEL abundance persistently decreased when tumors shrank in Case 23. (B) T790M rose with the tumor size in Case 24, which indicated an acquired therapeutic resistance to gefitinib. (C) Case 25 presented a change in T790M abundance after receiving AZD9291 treatment. cfDNA, circulating cell-free DNA; EGFR, epidermal growth factor receptor; Mut, mutant; FAM, 6-carboxyfluorescein; VIC, green fluorescent protein; 19DEL, exon 19 deletions; L858R, exon 21 L858R mutation (either L858R-1 or L858R-2); T790M, exon 20 T790M mutation.

had taken gefitinib for 6 months before the serial plasma collection started. Considering the L858R mutation detected by ARMS in the biopsied tumor specimens at the time of onset, the 5-plex panel (for assaying L858R and T790M) was applied. A decrease in L858R mutant abundance was observed in the first follow-up period, and T790M mutant abundance then rose, which is in accordance with the tumor size and indicated an acquired therapeutic resistance to gefitinib. Case 25 (Fig. 5C) is a 61-year-old male smoker with lung adenocarcinoma and bone metastases who had been treated with gefitinib for 10 months and developed resistance. This patient was assessed using the 5-plex panel assay for an EGFR activating-mutant profile, which was previously demonstrated by ARMS assays in tumor tissue. Applying the third-generation EGFR-TKI AZD9291 caused a changeover in the T790M mutant abundance and disease progress.

\section{Discussion}

In the present study, two multiplex ddPCR panels were established and quantitatively analyzed EGFR mutations in plasma cfDNA isolated from advanced NSCLC patients to assess their usefulness in EGFR-TKI decision-making. A previous study demonstrated the high carrying rate of EGFR mutations in Asian patients with advanced NSCLC; however, the coexistence of 19DEL and L858R mutants increased in only $0.8 \%$ patients (21). Thus, either of the multiplex ddPCR panels (assaying 19DEL and L858R as TKI-sensitive mutants and T790M as a TKI-resistant mutant) is capable of evaluating EGFR mutations for current clinical requirements.

Circulating cfDNA assays on tumor genetic information could serve as a 'liquid biopsy' to facilitate dynamic monitoring of EGFR mutations during treatment and could allow for constant optimization of personalized therapy (22). Moreover, circulating cfDNA mutant assays can help generate genetic profiles from patients incapable of having or reluctant to accept tumor biopsies. The amount of circulating cfDNA is higher in cancer patients than in healthy individuals due to the release of nucleic acids into the bloodstream by tumor cell apoptosis, necrosis and secretion (23). However, detecting EGFR mutations in circulating cfDNA remains a challenge due to its low abundance, which is attenuated in the overall complex genetic background. High-sensitivity methods have been explored in the past year. Scorpion-ARMS, denaturing high-performance liquid chromatography detection, peptide nucleic acid mediated polymerase chain reaction clamping and next-generation sequencing have been evaluated as EGFR mutant assays with plasma cfDNA from NSCLC patients and have detection sensitivities ranging from 20.7 to $65.79 \%$ of the sensitivities achieved using tumor tissue examination methods (24-27). The detectable abundance of the multiplex ddPCR panels in the current study ranged from 0.01 to $10 \%$. Applying plasma cfDNA assays to a ddPCR platform has greater detection sensitivity than the existing technologies for seeking specific mutations with ultra-low abundance.

The overall concordance rate in the present study between results generated from plasma samples by ddPCR and tumor tissues by ARMS was $80 \%$, which is similar to other studies, which have ranged from 80.0 to $94.19 \%$ concordance (19,28-30). Interestingly, the ddPCR assays performed on plasma cfDNA have noted additional EGFR mutants that were absent from the tumor tissue in two cases. Despite detection sensitivity issues, the contradiction in results could be due to the inter- or intra-tumor heterogeneity in tumor biopsy specimens $(31,32)$. The EGFR mutation status between primary tumors and metastatic tumors is reportedly different $(33,34)$. ddPCR assays were performed on a metastatic tumor collected from the lymph node of one patient and detected an additional 19DEL mutation. Plasma 
cfDNA containing genetic information from both primary and metastatic tumors can help overcome the boundedness due to tumor heterogeneity and selection bias in biopsy and can acquire more genetic profiling that is absent from a single snapshot. Plasma cfDNA may degrade without timely separation when collected in EDTA- $\mathrm{K}_{2}$-containing tubes without nuclease inhibitors (35); the authors suspected this limitation was the reason for the positive mutations detected in tumor tissues with negative results in plasma cfDNA in the study.

Several studies have demonstrated that changes in mutant abundance in plasma cfDNA are associated with the tumor burden and malignant progression $(30,36)$. Similarly, the results of our study inferred that EGFR mutant abundance in plasma cfDNA fluctuated according to changes in tumor size, which certified the practicality of our multiplex ddPCR panels in therapeutic evaluation and resistance monitoring. Either panel can be chosen flexibly, according to the mutant alleles generated by routine assays on tumor tissue specimens in a clinical setting, and can be applied to patients receiving TKIs to continually inspect $E G F R$ mutation abundance in plasma cfDNA. With its very short retention period in plasma, circulating cfDNA can reflect immediate tumor-associated changes (23). Thus, it can be monitored at short intervals, even less than the 2 months described in the present study, and can serve as the evidence for therapeutic regimen adjustments before tumor progression imaging is performed. By monitoring the changes in EGFR mutant abundance in plasma cfDNA, our multiplex ddPCR panels can provide an early indication of EGFR-TKI resistance. Patients in whom the post-treatment T790M mutation arose would then benefit from a new treatment plan using the new TKI, AZD9291 (37,38).

In this study, two multiplex ddPCR panels were put forward for analysis of multiple EGFR mutant alleles with therapeutic significance that are integrated into a single assay consuming minimal plasma sample from NSCLC patients. The application of these two panels in clinical settings will be practical, flexible, and time- and cost-saving. However, it should be noted that an LOB series was determined for each mutant based on our multiplex ddPCR panels developed in-house; these results should not be used to determine cutoffs for clinical decisions. The utility, feasibility and robustness of the multiplex ddPCR panels should be further examined in a larger-scale clinical trial.

\section{Acknowledgements}

The present study was supported by the National Natural Science Foundation of China (grant no. 81572064) and the Key Developing Disciplines of Shanghai Municipal Commission of Health and Family Planning (grant no. 2015ZB0201).

\section{References}

1. Torre LA, Bray F, Siegel RL, Ferlay J, Lortet-Tieulent J and Jemal A: Global cancer statistics, 2012. CA Cancer J Clin 65: 87-108, 2015.

2. Chen W, Zheng R, Baade PD, Zhang S, Zeng H, Bray F, Jemal A, Yu XQ and He J: Cancer statistics in China, 2015. CA Cancer J Clin 66: 115-132, 2016.
3. Zhou C, Wu YL, Chen G, Feng J, Liu XQ, Wang C, Zhang S, Wang J, Zhou S, Ren S, et al: Erlotinib versus chemotherapy as first-line treatment for patients with advanced EGFR mutation-positive non-small-cell lung cancer (OPTIMAL, CTONG-0802): A multicentre, open-label, randomised, phase 3 study. Lancet Oncol 12: 735-742, 2011.

4. Han JY, Park K, Kim SW, Lee DH, Kim HY, Kim HT, Ahn MJ, Yun T, Ahn JS, Suh C, et al: First-SIGNAL: First-line single-agent iressa versus gemcitabine and cisplatin trial in never-smokers with adenocarcinoma of the lung. J Clin Oncol 30: 1122-1128, 2012.

5. Mitsudomi T and Yatabe Y: Mutations of the epidermal growth factor receptor gene and related genes as determinants of epidermal growth factor receptor tyrosine kinase inhibitors sensitivity in lung cancer. Cancer Sci 98: 1817-1824, 2007.

6. Sequist LV, Waltman BA, Dias-Santagata D, Digumarthy S, Turke AB, Fidias P, Bergethon K, Shaw AT, Gettinger S, Cosper AK, et al: Genotypic and histological evolution of lung cancers acquiring resistance to EGFR inhibitors. Sci Transl Med 3: 75ra26, 2011

7. Yu HA, Arcila ME, Rekhtman N, Sima CS, Zakowski MF, Pao W, Kris MG, Miller VA, Ladanyi M and Riely GJ: Analysis of tumor specimens at the time of acquired resistance to EGFR-TKI therapy in 155 patients with EGFR-mutant lung cancers. Clin Cancer Res 19: 2240-2247, 2013.

8. Jänne PA, Yang JC, Kim DW, Planchard D, Ohe Y, Ramalingam SS, Ahn MJ, Kim SW, Su WC, Horn L, et al: AZD9291 in EGFR inhibitor-resistant non-small-cell lung cancer. N Engl J Med 372: 1689-1699, 2015.

9. Su KY, Chen HY, Li KC, Kuo ML, Yang JC, Chan WK, Ho BC, Chang GC, Shih JY, Yu SL and Yang PC: Pretreatment epidermal growth factor receptor (EGFR) T790M mutation predicts shorter EGFR tyrosine kinase inhibitor response duration in patients with non-small-cell lung cancer. J Clin Oncol 30: 433-440, 2012.

10. Hata A, Katakami N, Yoshioka H, Takeshita J, Tanaka K, Nanjo S, Fujita S, Kaji R, Imai Y, Monden K, et al: Rebiopsy of non-small cell lung cancer patients with acquired resistance to epidermal growth factor receptor-tyrosine kinase inhibitor: Comparison between T790M mutation-positive and mutation-negative populations. Cancer 119: 4325-4332, 2013.

11. Wang Z, Chen R, Wang S, Zhong J, Wu M, Zhao J, Duan J, Zhuo M, An T, Wang Y, et al: Quantification and dynamic monitoring of EGFR T790M in plasma cell-free DNA by digital PCR for prognosis of EGFR-TKI treatment in advanced NSCLC. PLoS One 9: e110780, 2014.

12. Reck M, Popat S, Reinmuth N, De Ruysscher D, Kerr KM and Peters S; ESMO Guidelines Working Group: Metastatic non-small-cell lung cancer (NSCLC): ESMO clinical practice guidelines for diagnosis, treatment and follow-up. Ann Oncol 25 (Suppl 3): iii27-39, 2014

13. Leighl NB, Rekhtman N, Biermann WA, Huang J, Mino-Kenudson M, Ramalingam SS, West H, Whitlock S and Somerfield MR: Molecular testing for selection of patients with lung cancer for epidermal growth factor receptor and anaplastic lymphoma kinase tyrosine kinase inhibitors: American society of clinical oncology endorsement of the College of American Pathologists/International Association for the study of lung cancer/association for molecular pathology guideline. J Clin Oncol 32: 3673-3679, 2014.

14. National Comprehensive Cancer Network: NCCN guidelines for patients. Version 1, 2015. Non-Small Cell Lung Cancer (S/OL). Accessed: November 6, 2015.

15. Taly V, Pekin D, Benhaim L, Kotsopoulos SK, Le Corre D, Li X, Atochin I, Link DR, Griffiths AD, Pallier K, et al: Multiplex picodroplet digital PCR to detect KRAS mutations in circulating DNA from the plasma of colorectal cancer patients. Clin Chem 59: 1722-1731, 2013.

16. Yung TK, Chan KC, Mok TS, Tong J, To KF and Lo YM: Single-molecule detection of epidermal growth factor receptor mutations in plasma by microfluidics digital PCR in non-small cell lung cancer patients. Clin Cancer Res 15: 2076-2084, 2009.

17. Watanabe M, Kawaguchi T, Isa S, Ando M, Tamiya A, Kubo A, Saka H, Takeo S, Adachi H, Tagawa T, et al: Ultra-sensitive detection of the pretreatment EGFR T790M mutation in non-small cell lung cancer patients with an EGFR-activating mutation using droplet digital PCR. Clin Cancer Res 21: 3552-3560, 2015.

18. Thermo Scientific. User Guide: Phusion site-directed mutagenesis kit. Accessed: January 4, 2015.

19. Nishino M, Jackman DM, Hatabu H, Jänne PA, Johnson BE and Van den Abbeele AD: Imaging of lung cancer in the era of molecular medicine. Acad Radiol 18: 424-436, 2011. 
20. Zhu G, Ye X, Dong Z, Lu YC, Sun Y, Liu Y, McCormack R, Gu Y and Liu X: Highly sensitive droplet digital PCR method for detection of EGFR-activating mutations in plasma cell-Free DNA from patients with advanced non-small cell lung cancer. J Mol Diagn 17: 265-272, 2015.

21. Shi Y, Au JS, Thongprasert S, Srinivasan S, Tsai CM, Khoa MT, Heeroma K, Itoh Y, Cornelio G and Yang PC: A prospective, molecular epidemiology study of EGFR mutations in Asian patients with advanced non-small-cell lung cancer of adenocarcinoma histology (PIONEER). J Thorac Oncol 9: 154-162, 2014

22. Heitzer E, Ulz P and Geigl JB: Circulating tumor DNA as a liquid biopsy for cancer. Clin Chem 61: 112-123, 2015.

23. Diaz LA Jr and Bardelli A: Liquid biopsies: Genotyping circulating tumor DNA. J Clin Oncol 32: 579-586, 2014.

24. Bai H, Mao L, Wang HS, Zhao J, Yang L, An TT, Wang X, Duan CJ, Wu NM, Guo ZQ, et al: Epidermal growth factor receptor mutations in plasma DNA samples predict tumor response in Chinese patients with stages IIIB to IV non-small-cell lung cancer. J Clin Oncol 27: 2653-2659, 2009

25. Douillard JY, Ostoros G, Cobo M, Ciuleanu T, Cole R, McWalter G, Walker J, Dearden S, Webster A, Milenkova T and McCormack R: Gefitinib treatment in EGFR mutated caucasian NSCLC: Circulating-free tumor DNA as a surrogate for determination of EGFR status. J Thorac Oncol 9: 1345-1353, 2014.

26. Kim HR, Lee SY, Hyun DS, Lee MK, Lee HK, Choi CM, Yang SH, Kim YC, Lee YC, Kim SY, et al: Detection of EGFR mutations in circulating free DNA by PNA-mediated PCR clamping. J Exp Clin Cancer Res 32: 50, 2013.

27. Couraud S, Vaca-Paniagua F, Villar S, Oliver J, Schuster T, Blanché H, Girard N, Trédaniel J, Guilleminault L, Gervais R, et al: Noninvasive diagnosis of actionable mutations by deep sequencing of circulating free DNA in lung cancer from never-smokers: A proof-of-concept study from BioCAST/IFCT-1002. Clin Cancer Res 20: 4613-4624, 2014.

28. Ishii H, Azuma K, Sakai K, Kawahara A, Yamada K, Tokito T, Okamoto I, Nishio K and Hoshino T: Digital PCR analysis of plasma cell-free DNA for non-invasive detection of drug resistance mechanisms in EGFR mutant NSCLC: Correlation with paired tumor samples. Oncotarget 6: 30850-30858, 2015 .

29. Seki Y, Fujiwara Y, Kohno T, Takai E, Sunami K, Goto Y, Horinouchi H, Kanda S, Nokihara H, Watanabe S, et al: Picoliter-droplet digital polymerase Chain reaction-based analysis of cell-free plasma DNA to assess EGFR mutations in lung adenocarcinoma that confer resistance to tyrosine-kinase inhibitors. Oncologist 21: 156-164, 2016.
30. Lee JY, Qing X, Xiumin W, Yali B, Chi S, Bak SH, Lee HY, Sun JM, Lee SH, Ahn JS, et al: Longitudinal monitoring of EGFR mutations in plasma predicts outcomes of NSCLC patients treated with EGFR TKIs: Korean lung cancer consortium (KLCC-12-02). Oncotarget 7: 6984-6993, 2016.

31. Taniguchi K, Okami J, Kodama K, Higashiyama M and Kato K: Intratumor heterogeneity of epidermal growth factor receptor mutations in lung cancer and its correlation to the response to gefitinib. Cancer Sci 99: 929-935, 2008

32. Bai H, Wang Z, Wang Y, Zhuo M, Zhou Q, Duan J, Yang L, Wu M, An T, Zhao J and Wang J: Detection and clinical significance of intratumoral EGFR mutational heterogeneity in Chinese patients with advanced non-small cell lung cancer. PLoS One 8: e54170, 2013.

33. Chen ZY, Zhong WZ, Zhang XC, Su J, Yang XN, Chen ZH, Yang JJ, Zhou Q, Yan HH, An SJ, et al: EGFR mutation heterogeneity and the mixed response to EGFR tyrosine kinase inhibitors of lung adenocarcinomas. Oncologist 17: 978-985, 2012.

34. Shimizu K, Yukawa T, Hirami Y, Okita R, Saisho S, Maeda A, Yasuda K and Nakata M: Heterogeneity of the EGFR mutation status between the primary tumor and metastatic lymph node and the sensitivity to EGFR tyrosine kinase inhibitor in non-small cell lung cancer. Target Oncol 8: 237-242, 2013.

35. Sillence KA, Roberts LA, Hollands HJ, Thompson HP, Kiernan M, Madgett TE, Welch CR and Avent ND: Fetal sex and RHD genotyping with digital PCR demonstrates greater sensitivity than real-time PCR. Clin Chem 61: 1399-1407, 2015.

36. Reinert T, Schøler LV, Thomsen R, Tobiasen H, Vang S, Nordentoft I, Lamy P, Kannerup AS, Mortensen FV, Stribolt K, et al: Analysis of circulating tumor DNA to monitor disease burden following colorectal cancer surgery. Gut 65: 625-634, 2016

37. Cross DA, Ashton SE, Ghiorghiu S, Eberlein C, Nebhan CA, Spitzler PJ, Orme JP, Finlay MR, Ward RA, Mellor MJ, et al: AZD9291, an irreversible EGFR TKI, overcomes T790M-mediated resistance to EGFR inhibitors in lung cancer. Cancer Discov 4: 1046-1061, 2014.

38. Jiang T and Zhou C: Clinical activity of the mutant-selective EGFR inhibitor AZD9291 in patients with EGFR inhibitor-resistant non-small cell lung cancer. Transl Lung Cancer Res 3: 370-372, 2014. 